Goldschmidt 2021 Abstract

https://doi.org/10.7185/gold2021.5909

\section{Carbon cycle dynamics in microbialite-hosting alkaline crater lakes as Precambrian analogs}

\author{
ROBIN HAVAS ${ }^{1}$, DR. CHRISTOPHE THOMAZO ${ }^{2}$, \\ PURIFICACIÓN LÓPEZ-GARCÍA ${ }^{3}$, DIDIER JÉZÉQUEL ${ }^{4}$, \\ MIGUEL INIESTO $^{3}$, DAVID MOREIRA ${ }^{3}$, EMMANUELLE \\ VENNIN $^{5}$, ROSALUZ TAVERA $^{6}$, ELODIE MULLER $^{7}$ AND \\ KARIM BENZERARA ${ }^{8}$ \\ ${ }^{1}$ Biogéosciences, CNRS UMR 6282, Université de Bourgogne \\ Franche-Comté \\ ${ }^{2}$ Laboratoire Biogéosciences, UMR CNRS 6282, Université de \\ Bourgogne Franche-Comté \\ ${ }^{3}$ Unité d'Ecologie, Systématique et Evolution, CNRS UMR \\ 8079, Université Paris Sud \\ ${ }^{4}$ Université de Paris-Institut de Physique du Globe de Paris- \\ CNRS, UMR 7154 \\ ${ }^{5}$ University of Bourgogne Franche-Comté \\ ${ }^{6}$ Departamento de Ecología y Recursos Naturales, Universidad \\ Nacional Autónoma de México \\ ${ }^{7} \mathrm{CNRS}$ - IMPMC \\ ${ }^{8}$ IMPMC, Sorbonne Université, CNRS UMR 7590, MNHN \\ Presenting Author: robin.havas@ubfc.fr
}

Microbialites represent one of the oldest traces of life on Earth (at least $\sim 3.5 \mathrm{Ga}$ ). However, numerous questions remain about their mechanisms and environments of formation throughout the geological record. In this regard, isotopic compositions of ancient microbialites are widely used, but require that we understand how isotopic signatures and microbial processes relate in modern microbialites and how elements are cycled within their growth's environment. Notably, carbon is a central constituent in microbialites, precipitating in both organic and mineral phases and a key element in Earth's climate.

Here, we quantitatively describe the carbon cycle of four stratified alkaline crater lakes in Mexico. These lakes are chemically diverse and harbor varying amounts of microbialites developing across an oxycline, hence appearing as good analogs to Precambrian environments. We measured concentrations and isotopic compositions of dissolved organic and inorganic carbon (DOC, DIC) and particulate organic carbon (POC) throughout the water columns, as well as organic and carbonate carbon within microbialites and bottom lake sediments.

DIC is the main $\mathrm{C}$ reservoir in water columns ([DIC] from 7 to $35 \mathrm{mM})$. The $\delta^{13} \mathrm{C}_{\text {DIC }}$ show either subtle variations $(\sim 0.5 \%)$ interpreted to reflect organic matter remineralization or strong variations (increasing by $14 \%$ from the water column to the first $\mathrm{cm}$ of drill core pore waters) likely driven by mantle degassing and/or bottom lake methanogenesis. The POC reservoir size is small compared to the DOC $(0.05 \mathrm{mM} v s .2 .8 \mathrm{mM}$ on average $)$, the latter representing from 3 to $14 \%$ of total carbon. The $\delta^{13} \mathrm{C}_{\mathrm{DOC}}$ and [DOC] markedly increased within or just below the oxycline (on average $+7 \%$ and a 6 -fold increase, respectively), which strongly impacts the overall carbon isotopic mass balance, creating a ${ }^{13} \mathrm{C}$-depleted reservoir in the oxycline of three of the studied lakes. Though often dismissed, DOC thus holds an important part of $\mathrm{C}$ cycles in these lakes, constituting a sizeable and evolving reservoir, which role on the microbialites precipitation and isotopic signatures needs to be further explored. These results, combined with parallel "meta-omic" studies on the microbial diversity and function should provide an integrative understanding of $\mathrm{C}$ cycle dynamics in these systems. 